$19^{\text {th }}$ International Conference on Renewable Energies and Power Quality (ICREPQ'21)

Almeria (Spain), $28^{\text {th }}$ to $30^{\text {th }}$ July 2021

Renewable Energy and Power Quality Journal (RE\&PQJ)

ISSN 2172-038 X, Volume No.19, September 2021

\title{
Possible Link Between Climate Change and Extraordinary Wildfires in Australia, the Amazon and Western United States
}

\author{
M. Brajkovic ${ }^{1}$, T. Carter ${ }^{2}$, C. Cook $^{3}$, and A. Pourmovahed ${ }^{4}$ \\ ${ }^{1}$ Mechanical Engineering Student \\ Phone: +001 708515 6355, e-mail: braj9895@kettering.edu \\ ${ }^{2}$ Mechanical Engineering Graduate Student \\ Phone: +001 810358 7151, e-mail: cart5273@kettering.edu \\ ${ }^{3}$ Mechanical Engineering Student \\ Phone +001 (800) 955-4464, e-mail: cook2872@kettering.edu \\ ${ }^{4}$ Professor of Mechanical Engineering \\ Phone: +001 810762 9758, e-mail: apourmov@ kettering.edu
}

Kettering University

Flint, Michigan, U.S.A. 48504

\begin{abstract}
Areas with dry climates have recently become more vulnerable to wildfires as the soil and air moisture have been changing because of greenhouse gasses in the atmosphere. Areas especially impacted are Australia, the Amazon, and western United States. The common factors at these locations are a dry environment and brush or forests fueling the fires once they start. As the climate continues to change, less moisture is present in the ground in these areas. This proliferates the susceptibility to wildfire. Prevention methods for inhibiting wildfires include reducing our carbon footprint, using care around campfires and other causes of wildfire, as well as routine thinning and removal of excess vegetation. The purpose of this study was to determine whether there is a link between Climate Change and the extraordinary magnitude, intensity, and frequency of recent wildfires. Although it is not possible to link all these wildfires directly and undeniably to Climate Change, the data examined clearly point to a strong possibility that such a link exists.
\end{abstract}

Key words. Wildfire, Global Warming, Climate Change, Vapor Pressure Deficit

\section{Introduction}

Climate Change and the resulting increase in average global temperature is nothing new. Since the beginning of the Industrial Revolution, there has been a significant increase in $\mathrm{CO}_{2}$ emissions into the atmosphere. The $\mathrm{CO}_{2}$ concentration in the atmosphere has climbed steadily from 315 to over $415 \mathrm{ppm}$ since 1958 . Another contributor to Climate Change, methane gas, has also seen a similar trend. These increases in atmospheric greenhouse gasses have begun to show unintended consequences to the climate and the planet. Year after year, the average temperature of the earth is increasing. This has a direct effect in several key areas of the world, including the polar ice caps, the rain forests, as well as dry areas which are prone to fire. These areas include Australia, The Amazon, western United States, as well as Europe.

Throughout this article, key factors contributing to the higher probability of wildfires, as well as the frequency and impact of the wildfires in the areas mentioned above, will be discussed. As the link between Climate Change and the extraordinary increase in frequency and magnitude of wildfires is addressed, the focus will be on methods of reducing the likelihood of wildfires. Included are methods such as vegetation removal, separation of fuel sources to reduce spread of wildfires, as well as reducing carbon emissions to reduce the impact of Climate Change.

\section{Wildfire History, Causes, and Fighting Techniques}

Wildfire is defined as uncontrolled, unplanned burning of combustible vegetation in rural or urban areas. Wildfires range in size significantly from as small as an out-ofcontrol campfire to millions of acres. They spread quickly, up to about $20 \mathrm{~km} / \mathrm{h}$ (about $12 \mathrm{mph}$ ) and are a significant threat to both human and animal habitation.

Although wildfires from natural causes have existed for millions of years, there has been an increase in the postmodern age of civilization. According to the Insurance Information Institute [1], in 2020 more than 4.2 million ha (10.3 million acres) burned in the United States. This compares to 1.9 million ha (4.7 million acres) in 2019. In the State of California, five of the top 20 largest wildfires took place in 2020. 
Fig. 1 is an illustration of the potential of wildfires in western United States. California has a significant percentage of its area susceptible to many fires.

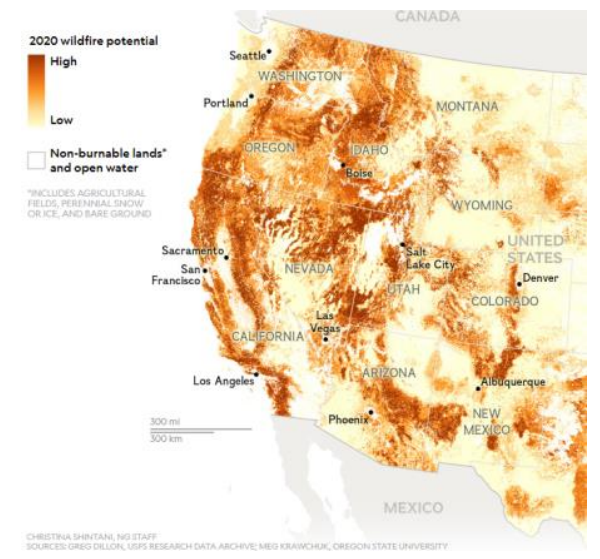

Fig. 1. Location of wildfires in western United States [2]

The main cause of modern wildfires is human activity. They can be started in many ways, such as campfires left unattended or not extinguished, wind on hot embers, downed power lines, discarded flammable tobacco products, fireworks, spent ammunition, as well as intentional arson. The remaining causes of wildfires are natural phenomena, such as lightning strikes, volcanic eruptions, decomposition of materials, or occasionally from the sunlight focusing through a lens-like transparent mineral similar to a magnifying glass.

Wind spreads fire by transporting hot or flaming material to unburnt areas, as well as preheating new fuel sources and reducing their moisture content, proliferating the rate at which new areas catch fire. Wildfires move faster up inclined surfaces, as heat naturally rises, and fresh fuel and oxygen are readily available at the top of the flame.

The most dangerous effect of wildfires is that humans tend to inaccurately estimate the distance a fire is away from them. This can lead to a sense of false security and safety, and a delayed evacuation time in emergency situations. Humans gauge the speed of an object by the relative change in size of the object. Fires continuously move and change in size; hence their location is difficult to judge. Once they are too close, it may be too difficult to evacuate safely.

There are two methods of combating wildfires. The first method is prevention. Fuel sources such as dense forests and grasslands can be burnt in prescribed fires to thin out or separate large areas of vegetation. By burning these areas during off seasons, not only is wildfire possibility reduced, but the fires can be more easily controlled. In addition to burning vegetation, areas of dense material can be physically separated from each other with herbicides, grazing animals, or digging the underbrush down to the bare earth.

Once wildfires start, fighting them includes the methods used for prevention, separating and thinning fuel sources. In addition to this, prewetting areas in the fire path can help slow it down or divert its path. Large tank vehicles and helicopters filled with fire suppression chemicals such as water and dirt are used to bring wildfires under control. This is often a large undertaking as these fires can be thousands of hectares across at a time. Digging flame lines can also be used to separate vegetation and other fuel sources, helping control the path and severity of fires.

As shown in Fig. 2, the intensity of a wildfire can be overwhelming. The fires produce a large amount of smoke and soot as well as $\mathrm{CO}_{2}$. This hampers visibility for the firefighters. When people need to evacuate areas which are ablaze, belongings including vehicles are left behind to succumb to the fire.

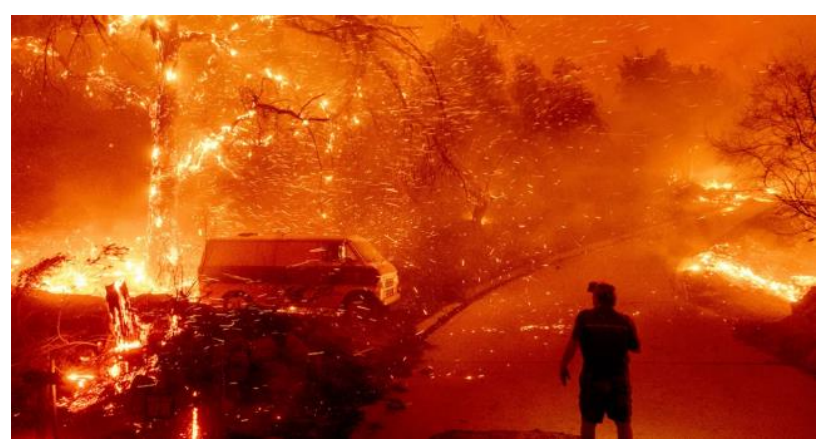

Fig. 2. Wildfire in Orange County, California, 3 Dec. 2020 [3]

The best way to prevent a wildfire is to avoid generating a fire source. Being more diligent in controlling campfires and other activities using fire, such as grilling and using fireworks, can go a long way in prevention of wildfires. Since Climate Change may increase the likelihood of a wildfire to become uncontrollable, reducing our carbon footprint can create an environment less prone to wildfires.

\section{Climate Change and Wildfire}

The leading Climate Change contribution to wildfire propagation is through an increase in temperature-induced vapor pressure deficit. Vapor pressure deficit (VPD, in $\mathrm{kPa}$ ) is related to the difference between the amount of moisture in the air and how much moisture the air can hold when it is fully saturated.

Since 1961, the VPD has increased notably across the western United States with the strongest increase in the southwest [4]. These trends have been primarily driven by warmer climate caused by global warming, which in turn has increased the VPD. At higher temperatures, the air becomes "drier" and can take more moisture out of plants, soil, and vegetation.

Fig. 3. Shows the 1981-2010 mean July maximum vapor pressure deficit for the Contiguous United States [5]. Not surprisingly, the regions experiencing high VPD correlate moderately well with the location of wildfires in western United States (Fig. 1).

Soil aridity is the deficiency of moisture in soil content. While the VPD is a fair determinant of wildfire likelihood, it almost entirely neglects the effect of rainfall in a region. If a plant is dried out by the atmosphere or a disappearing water source it becomes better kindling for a fire. Plant 
dryness is entirely linked to the soil beneath it. Lesser levels of water in the soil are going to mean lesser amounts of moisture in the plant. As shown in Fig. 4, since 1984, the extent of forest fires has increased at a proportional linear rate with the fuel aridity [6]. Comparing the data for the first 17 years of the $21^{\text {st }}$ Century (red dots) to the data for the last 15 years of the $20^{\text {th }}$ Century (blue dots) suggests a link to Global Warming.

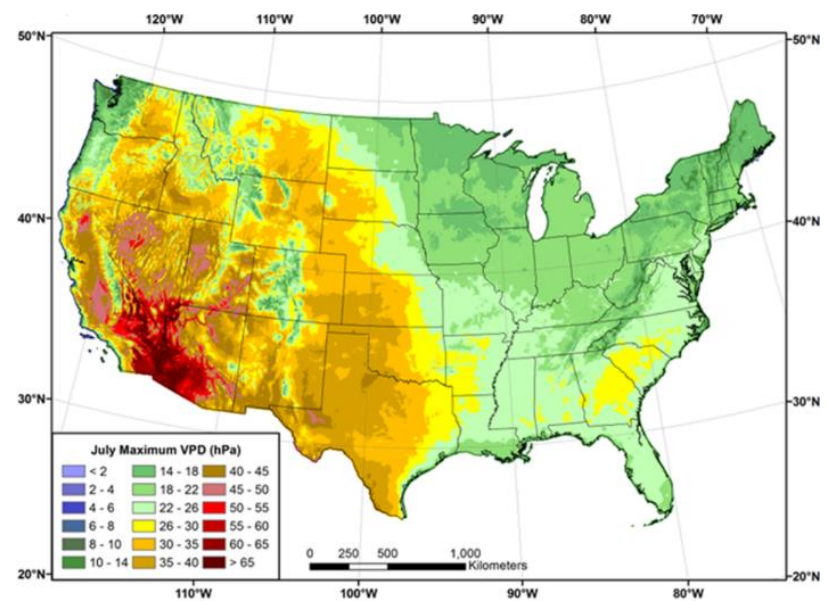

Fig. 3. 1981-2010 mean July max. vapor pressure deficit [5]

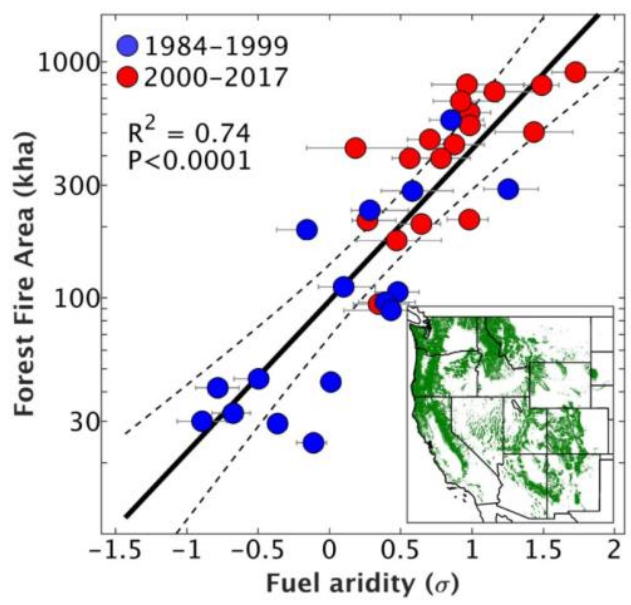

Fig. 4. Forest fire area vs. fuel (vegetation) aridity [6]

Fig. 5 depicts the Climate Feedback Loop [7] and explains how wildfire damage intensifies over time. The two most accurate variables in determining whether an area is susceptible to wildfire damage are the VPD (vapor pressure deficit, dependent on humidity and temperature) and Soil Aridity. Both variables have a positive correlation with the amount of carbon dioxide in the atmosphere. As $\mathrm{CO}_{2}$ levels increase over time, global temperatures rise. The increase in global temperature creates conditions that result in more moisture being pulled from plants and the soil, because warmer air is more capable of drawing moisture out of vegetation and the soil. Because of this, plants that draw $\mathrm{CO}_{2}$ out of the air either become weakened or die [7].
Fires and the Climate Feedback Loop

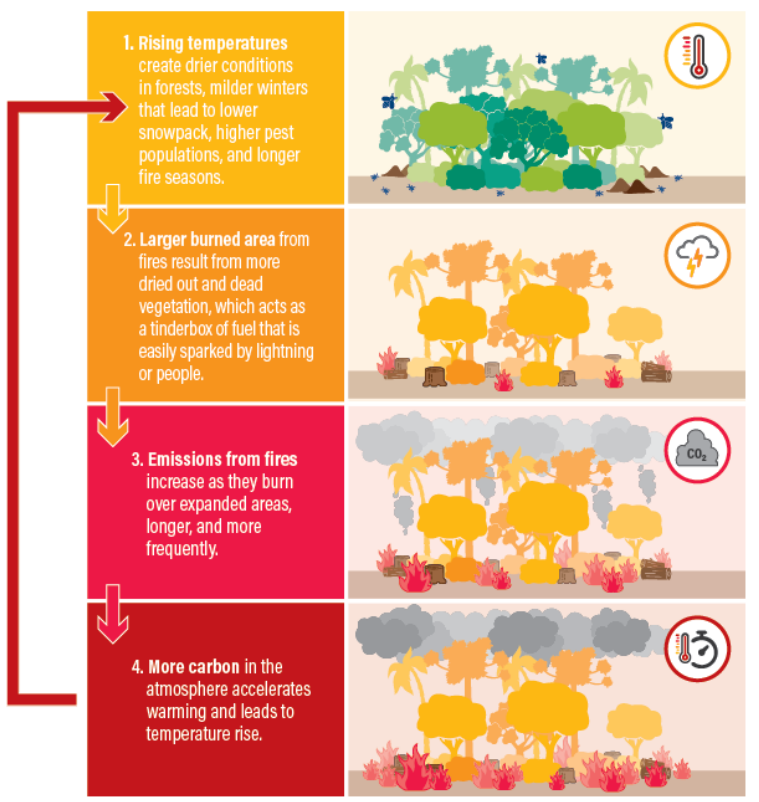

Source: Global Forest Watch

WORLD RESOURCES INSTITUTE

Fig. 5. Fires and the climate feedback loop [7]

As $\mathrm{CO}_{2}$ levels rise, not only does the likelihood of wildfires increase, but this is also associated with a decrease in plant life that is capable of filtering $\mathrm{CO}_{2}$. When wildfires occur, these plants burn and release the $\mathrm{CO}_{2}$ they have stored back into the atmosphere. Hence the feedback loop, the wildfires will release $\mathrm{CO}_{2}$ and increase the likelihood of another wildfire occurring [7].

In addition to wildfires growing in both magnitude and frequency, so is the length of the season in which they are more likely to occur. Climate Change is altering the seasonal snow and rain patterns across the world, leading to extended periods of time when fires are more likely to occur. Springtime is arriving earlier than in the past, and the snowpack from winter, contributing to around $30 \%$ of the summer water needs of vegetation is melting earlier. This means there is less moisture to last through the hotter portions of the year, leading to dryer plants and soil, increasing the likelihood of wildfires.

From the perspective of $\mathrm{CO}_{2}$ production, generally about 1.9 $\mathrm{kg}$ of $\mathrm{CO}_{2}$ are emitted for each $1 \mathrm{~kg}$ of wood burned. Assuming a clear-cut method of vegetation removal, there is an average of 87 tons of wood per acre [8]. According to [1] in the year 2020, 10.3 million acres (4.2 million ha) have burned in western United States. This translates to 896 million tons of wood burned which has produced $1.7 \times 10^{12}$ $\mathrm{kg}$ of $\mathrm{CO}_{2}$. For perspective, a typical passenger car emits 4.6 metric tons of carbon dioxide in a single year, so the $\mathrm{CO}_{2}$ produced by wildfire in western United States is equivalent to an additional 370 million vehicles on the road. As discussed, $\mathrm{CO}_{2}$ emissions are a significant contributor to global warming which can lead to an increased frequency of wildfires. 


\section{Recent Major Wildfires}

Throughout history, there have always been major fires raging throughout the earth but recently, warmer air and lower precipitation combined with strong winds have resulted in extraordinary wildfires in many parts of the world. Some of the causes of these fires can be attributed to Climate Change.

Early in 2020, Australia began experiencing major fires burning across the country. From January to November, 46 million acres (18.6 million ha) had burned. About 3 billion animals were killed or harmed by the wildfires [9]. Extreme heat following the driest spring on record has been blamed for this catastrophe. Studies have shown that the fires were initiated by humans.

The Amazon rainforest also experienced unusually devastating wildfires in 2020. The Amazon rainforest stretches across 9 separate countries in South America. A total of 6.9 million square kilometers (2.72 million square miles), with $2 / 3$ of the forest located in Brazil. In the Amazon there are 16,000 tree species and 390 billion individual trees [10]. In September 2020, Satellites recorded 32,017 fires in the Amazon rainforest, a $61 \%$ increase from the same month in 2019 [11]. A lot of the Amazon wetlands are home to jaguars. According to [12], 23\% of the wetlands burned and have left many Jaguars "wandering the blackened wasteland", "starving or going thirsty, with paws burnt to the bone, lungs blackened by smoke".

The fires in the western portion of the United States have been raging since 2017. Unfortunately, the United States has struggled to tame these wildfires. From the beginning of 2020 to December 18, about 57000 wildfires were reported. According to [1] in the year 2020, 10.3 million acres (4.2 million ha) have burned in western United States, compared with 4.7 million acres in 2019. Five of the top 20 largest California wildfires occurred in 2020. California has seen extreme heat and drought recently. This has caused wildfires to spread quickly.

Fire Radiative Power (FRP) is determined from the mid infrared signal emitted by actively burning fires and captured by satellites. It is linearly related to the amount of biomass combusted. Fig. 6 shows the radiative power of wildfires in California. The 2020 fire radiative power is remarkably larger than previous years.

\section{California fire radiative power (FRP)}

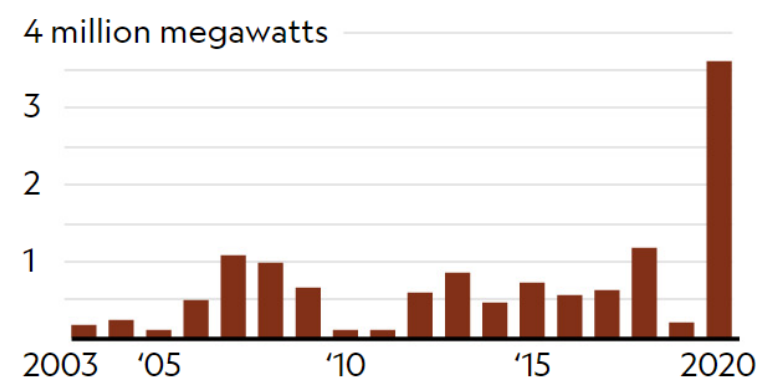

Fig. 6. Radiative power of California wildfires [2]
Over the past two decades, Mediterranean countries have invested about 200 billion euros in their fire prevention tactics and equipment [13]. This includes more firefighters, planes, and training for their locals who live in dry areas. After these actions took place, fires have ravaged less in these countries compared to the western United States and Australia. Fig. 7 shows the decline in burnt area in these countries due to the investment and support of firefighting. The total amount has gone from 557 thousand burnt hectares to around 344 thousand burnt hectares. This is an astonishing success which can be attributed to the investment these European countries have made in their firefighting efforts.

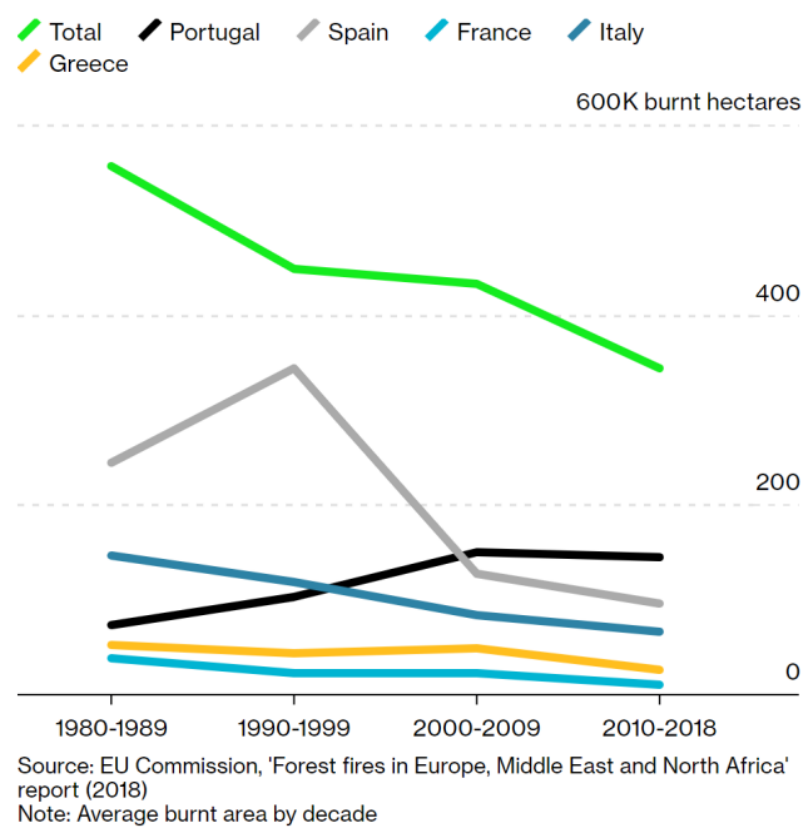

Fig. 7. Burnt area in large Mediterranean countries [13]

Another occurrence observed in Europe, Australia and elsewhere is called Pyrocumulonimbus (Fire Cloud). This is when the ashes and smoke from fires advance over the seas and oceans and the moisture from these bodies of water causes lightning to occur which spreads the fires miles away from the original source [13]. Fig. 8 shows a pyrocumulonimbus cloud forming from a fire in California. When a pyrocumulonimbus is formed, it becomes impossible to stop the fire.

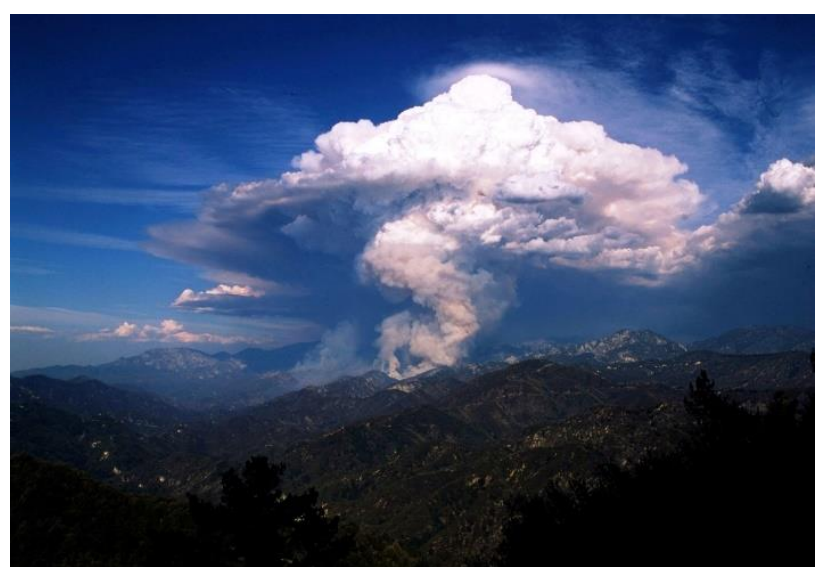

Fig. 8. A pyrocumulonimbus in California [14] 


\section{Cost of Wildfires}

Not only does a pyrocumulonimbus have a potential to spread wildfires over large areas, but it can also lead to acid rain and smog in the surrounding areas. This acid rain can damage crops, resulting in loss of produce. Therefore, not only do wildfires cause direct damage to the areas on fire, but they also have the potential for higher cost to surrounding communities.

Fig. 9 shows the estimated damage caused by wildfires in Europe from a purely financial perspective [15]. Throughout Europe, the cost of wildfires ranges significantly depending on location and the severity of the fire. It can range from 10 to 78,000 Euros per hectare. The Scandinavian section of Europe has much higher cost no matter the severity of the fire, as shown by the darker region in the figure. This corresponds to Sweden, Finland, and Norway, which contain mountainous regions with sizable forests.

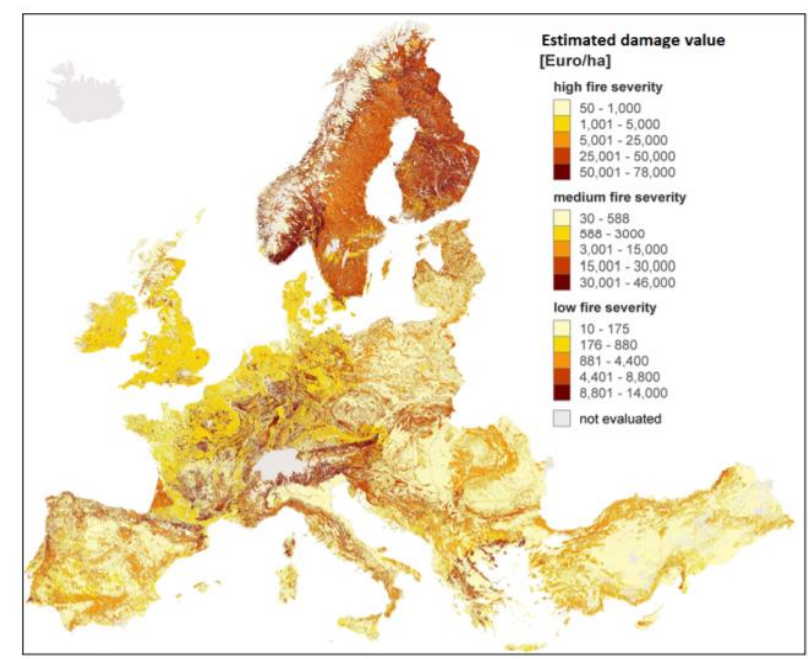

Fig. 9. Estimated wildfire damage value in Europe according to low, medium and high fire severity scenarios [15]

\section{Conclusions}

In recent years, severe and unprecedented wildfires have devastated many communities in several continents. Many millions of hectares have burned in Australia, the Amazon and western United States. These fires have also resulted in dozens of people losing their lives. Billions of animals were killed or harmed in the 2020 Australian wildfires.

Although it is not possible to link all these wildfires directly and undeniably to Climate Change, the data (e.g., Figs. 3, 4 and 6) clearly point to a strong possibility that such a link exists.

It is our opinion that Climate Change has contributed to the frequency and intensity of wildfires in all the nations discussed. These fires have affected not only humans but also billions of animals. Human negligence is also a contributing factor.
In many parts of the world, the vapor pressure deficit is increasing along with the climate. Areas already sensitive to wildfire have become even more volatile. Furthermore, the $\mathrm{CO}_{2}$ emitted from wildfires exacerbates the impact of global warming on frequency and severity of wildfires.

Most wildfires are caused by human activity, directly or indirectly. If we reduce greenhouse gas emissions significantly, the earth can better absorb the $\mathrm{CO}_{2}$, moderate the Climate Change, and reduce the frequency and intensity of wildfires.

Humans must focus on diligently preventing causes of wildfires as well as reducing the volatility of the environment available to the fires. They have the responsibility to act, as the current trajectory of Climate Change will only lead to higher rates and intensity of wildfires and other environmental repercussions.

\section{References}

[1] Facts + Statistics: Wildfires. (20 Oct. 2020). Retrieved 20 Dec. 2020, https://www.iii.org/fact-statistic/facts-statistics-wildfires

[2] Borunda, A., "The science connecting wildfires to climate change," National Geographic, 17 Sep. 2020 , https://www.nationalgeographic.com/science/2020/09/climatechange-increases-risk-fires-western-us/

[3] Rice, D., "Endless wildfire season sets record as more winds threaten power outages in Southern California" USA Today. 23 Dec. 2020, California wildfires: Power outages possible; Santa Ana winds threaten (usatoday.com)

[4] Gabbert, B., "The Role of Vapor Pressure Deficit in Wildland Fire," Wildfire Today, 26 Jan. 2015 , https://wildfiretoday.com/2015/01/26/the-role-of-vapor-pressuredeficit-in-wildland-fires

[5] Daly, Chris \& Smith, Joseph \& Olson, Keith. (2015), "Mapping Atmospheric Moisture Climatologies across the Conterminous United States," PloS one. 10. e0141140. 10.1371/journal.pone.0141140.

[6] Abatzoglou, J.T., and Williams, A.P., "Impact of Anthropogenic Climate Change on Wildfire across Western US Forests." PNAS, National Academy of Sciences, 10 Oct. 2016, www.pnas.org/content/early/2016/10/05/1607171113

[7] Harris, N., Munroe, T. and Levin, K., "6 Graphics Explain the Climate Feedback Loop Fueling US Fires." World Resources Institute, 16 Sep. 2020, 2020 US Fires and the Climate Feedback Loop | World Resources Institute (wri.org)

[8] Thomas, N., "How Many Tons of Wood are on an Acre of Land?," 13 Aug. 2018, How Many Tons of Wood are on an Acre of Land? (forest2market.com)

[9] Givetash, L., "Australian wildfires declared among the 'worst wildlife disasters in modern history'," NBC News (28 Jul. 2020), https://www.nbcnews.com/news/world/australian-wildfiresdeclared-among-worst-wildlife-disasters-modern-historyn1235071 
[10] Butler, R.A., "10 Facts about the Amazon Rainforest in 2020," (12 Feb. 2020), MONGABAY

https://rainforests.mongabay.com/amazon/amazon-rainforestfacts.html

[11] The Guardian, "Brazil's Amazon rainforest suffers worst fires in a decade," Retrieved December 29, 2020 , https://www.theguardian.com/environment/2020/oct/01/brazilamazon-rainforest-worst-fires-in-decade

[12] Spring, J., "Burned jaguars, fire tornadoes: Blazes in Brazil wetland deliver climate warning," Reuters, (14 Sep. 2020)

Burned jaguars, fire tornadoes: Blazes in Brazil wetland deliver climate warning (yahoo.com)
[13] Lombrana, L.M., "Europe's New Trick Against Wildfires: Let It Burn," 29 Sep. 2020, Europe's New Trick Against Wildfires: Let It Burn - Bloomberg

[14] Wikipedia, Pyrocumulus cloud in the Angeles National Forest California - Flammagenitus cloud - Wikipedia

[15] Camia, A., Libertá, G. and San-Miguel-Ayanz, J., "Modeling the impacts of climate change on forest fire danger in Europe, Sectorial results of the PESETA II Project," JRC Technical Reports, 2017 ,

Fire_danger_forecast_Climate_Change_simulations_PesetaII_fi nal06.03.2017.docx (core.ac.uk) 